\title{
TAMAN EDUKASI
}

\author{
Dorin Joe $^{1)}$, Mieke Choandi ${ }^{2)}$ \\ ${ }^{1)}$ Program Studi S1 Arsitektur, Fakultas Teknik, Universitas Tarumanagara, dorinjoe95@gmail.com \\ ${ }^{2)}$ Program Studi S1 Arsitektur, Fakultas Teknik, Universitas Tarumanagara, miekec@ft.untar.ac.id
}

\begin{abstract}
Abstrak
Budaya Jakarta merupakan budaya mestizo, atau sebuah campuran budaya dari beragam etnis. Salah satu permasalahan yang tengah dihadapi oleh warga Jakarta belakangan ini adalah mengenai perilaku masyarakat yang masih memiliki pendidikan yang kurang atau tidak semua tinggi, sehingga gejolak dalam politik pun terjadi. Gejolak permasalahan politik ini berlari kearah permasalahan agama agar masyarakat lebih mudah untuk dihasut atau diarahkan demi kepentingan para politikus. Oleh karena itu hiburan yang akan diberikan kepada masyarakat menangani permasalahan ini adalah dengan cara menyediakan tempat hiburan yang mengedukasi sekaligus memberi kesenangan kepada semua lapisan masyarakatnya, dan dapat berbaur dengan semua jenis kalangan masyarakat yang ada di Jakarta.
\end{abstract}

Kata kunci: edukasi, mestizo, politikus, taman hiburan

\begin{abstract}
Jakarta culture is a culture of mestizo, or a mixture of cultures from various ethnicities. One of the problems being faced by Jakarta residents lately is about the behavior of people who still have education that is less or not all high, so that turmoil in politics also occurs. The turmoil of political problems ran towards religious issues so that people were easier to incite or directed towards the interests of politicians. Therefore the entertainment that will be given to the community to deal with this problem is by providing entertainment venues that educate and at the same time give pleasure to all levels of society, and can blend with all types of people in Jakarta.
\end{abstract}

Keywords: amusement parks, education, mestizo, politicus

\section{PENDAHULUAN Latar Belakang}

Kota Jakarta menggambarkan sebuah kota yang padat penduduk, memiliki berbagai aneka suku, budaya, serta agama yang berbeda-beda. Kepadatan penduduk yang tinggi, aktivitas yang padat merupakan permasalahan kota yang dihadapi oleh warga Jakarta setiap hari. Dari adanya aneka suku, budaya, dan agama yang berbeda-beda, timbul perbedaan ekonomi, sosial, dan budaya yang tajam, termasuk pendidikan, sehingga orang-orang yang memiliki pendidikan rendah akan mudah untuk dihasut. Salah satu contoh yang belum lama terjadi yakni peristiwa 212 dimana dikarenakan isu sara serta penghinaan agama.

Pandangan hidup suatu bangsa berasal dari nilai-nilai budaya yang dijunjung tinggi. Setiap masyarakat yang mendiami suatu daerah di Indonesia pastilah mempunyai ciri kebudayaan. Pancasila sebagai pandangan hidup bangsa secara keseluruhan merupakan intisari dari nilainilai budaya masyarakat yang majemuk. Pancasila memiliki ciri yang khas dalam kebudayaan masyarakat, oleh karena itu tidak dapat dipisahkan dari kehidupan masyarakat Indonesia dan merupakan ciri khas yang membedakan bangsa Indonesia dengan bangsa-bangsa lain di dunia. Pengaplikasian nilai-nilai Pancasila sebagai dasar falsafah negara adalah untuk mencegah terjadinya konflik antar suku, agama, dan daerah serta menghindari adanya tindakan separatis untuk memisahkan diri dari Negara Kesatuan Republik Indonesia. Pemahaman nilai-nilai Pancasila akan menciptakan dan menumbuhkan jiwa persatuan dan kesatuan. Oleh karena itulah Negara Kesatuan Republik Indonesia mencantumkan semboyan Bhineka Tunggal Ika 
pada lambang Negara, Persatuan dan Kesatuan tidak boleh mematikan keanekaragaman dan kemajemukan sebagaimana kemajemukan tidak boleh menjadi faktor pemecah belah, tetapi harus menjadi sumber daya yang kaya untuk memajukan kesatuandan persatuan itu. Pancasila merupakan alat pemersatu Bangsadari perpecahan, konflik yang terjadi ditengah lapisan masyarakat, dengan jalan setiap masyarakat harus mampu menjiwai secara mendalam dan mengaplikasikannya dalam kehidupansehari-hari. Oleh karena itu untuk menetralkan permasalahan ini kota Jakarta membutuhkan adanya tempat wisata untuk warga nya sebagai wadah yang mampu menjadi destinasi dan atraksi wisata di tengah kepadatan dan dinamika ruang metropolis (Jakarta).

Menciptakan ruang wisata untuk warga Jakarta agar dapat menjadi atraksi wisata yang baik, dapat menghibur dan memberikan rasa senang bagi warga Jakarta. Budaya Jakarta merupakan budaya mestizo, atau sebuah campuran budaya dari beragam etnis. Jakarta merupakan daerah tujuan urbanisasi berbagai ras di dunia dan berbagai suku bangsa di Indonesia, serta agama yang dianut oleh penduduk DKI Jakarta beragam. Salah satu permasalahan yang tengah dihadapi oleh warga Jakarta belakangan ini adalah mengenai perilaku masyarakat yang masih memiliki pendidikan yang rendah, oleh karena itu membuat mereka tidak memiliki nalar berpikir yang sehat, sehingga mudah dihasut dan dipengarhi oleh profokator politik. Gejolak permasalahan politik yang paling memukau adalah kearah sara, terutama permasalahan agama agar masyarakat lebih mudah untuk dihasut atau diarahkan demi kepentingan para politikus. Oleh karena itu hiburan yang akan diberikan kepada masyarakat adalah dengan cara menyediakan tempat hiburan yang dapat mengedukasi sekaligus memberi kesenangan kepada semua lapisan masyarakatnya, setiap fasilitas/ hiburan dapat berbaur dengan semua jenis kalangan masyarakat yang ada di Jakarta khususnya warga di sekitar proyek tersebut.

\section{METODE}

Asal mula ide proyek yang akan dibangun dikarenakan isu permasalahan karena isu sara dan penghinaan agama di Jakarta. Kriteria lokasi yang diinginkan untuk proyek wisata:

- Lokasi yang memiliki isu permasalahan mengenai keagamaan yang cukup kuat.

- Tidak terletak di dalam kawasan kelas tinggi.

- Lokasi yang mudah didatangi oleh masyarakat kelas menengah keatas maupun kebawah.

- Memiliki kawasan yang dekat dengan unsur air seperti danau, guna untuk salah satu pemandangan yang akan terdapat di kawasan proyek.

- Terletak di wilayah antara 2 etnis atau lebih.

Permasalahan yang tengah dihadapi oleh warga Jakarta belakangan ini adalah mengenai perilaku masyarakat yang berkaitan dengan isu agama belakangan ini. Isu-isu yang ada diantara nya muncul dari salah satunya adalah politik, sebagai contoh diantara lain:

a) Kasus pendirian rumah ibadat dan tempat ibadat.

b) Adanya tindakan kekerasan terutama terhadap kelompok minoritas

c) Kasus Ahok menista agama

d) Pengeboman di berbagai gereja (seperti di kota Surabaya). 

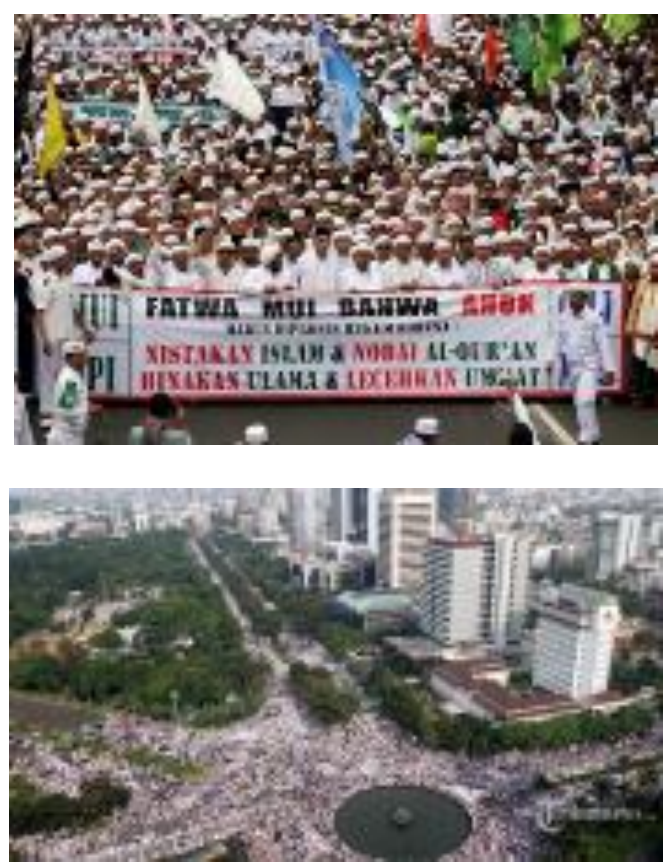

Gambar 1. Demo tolak Ahok yang diduga penista agama Sumber : https://tangselmedia.com

Salah satu cara untuk mengatasi permasalahan isu ini dengan membangun sebuah taman hiburan yang dapat membangun masyarakat yang bermoral dan berjiwa kesatuan sesuai dengan dasar negara, yakni Pancasila. Karena nilai-nilai Pancasila adalah nilai-nilai luhur yang menjadi acuan bersama dari kehidupan kita. Negara kita harus membangun ruang publik, ruang dialog agar kelompok-kelompok yang ada saling berinteraksi. Pancasila dalam setiap diri bangsa untuk mencegah terjadinya konflik antar suku, agama, dan daerah serta menghindari adanya tindakan separatis untuk memisahkan diri dari Negara Kesatuan Republik Indonesia. Pancasila merupakan alat pemersatu Bangsa dari perpecahan, konflik yang terjadi ditengah lapisan masyarakat, dengan jalan setiap masyarakat harus mampu menjiwai secara mendalam dan mengaplikasikannya dalam kehidupansehari-hari.

\section{DISKUSI DAN HASIL}

\section{Pengembangan Program Arsitektur yang terdapat di lokasi}

Fenomena isu permasalahan keagamaan yang terjadi di kota Jakarta pada masa belakangan ini adalah salah satunya karena isu permasalahan keagamaan. Dari isu ini diangkatlah sebuah program yang akan dituangkan kedalam sebuah lokasi guna untuk dapat memberikan edukasi kepada anak-anak maupun orang tua untuk dapat berpikir lebih luas, serta dapat saling bersosialisasi satu dengan yg lainnya tanpa memandang suku, agama, dan ras.

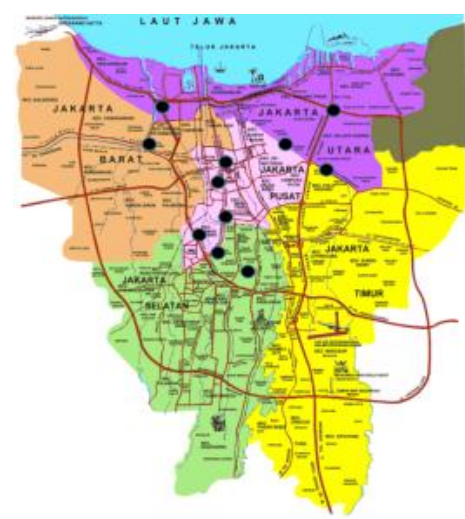

Gambar 2. Peta Jakarta 


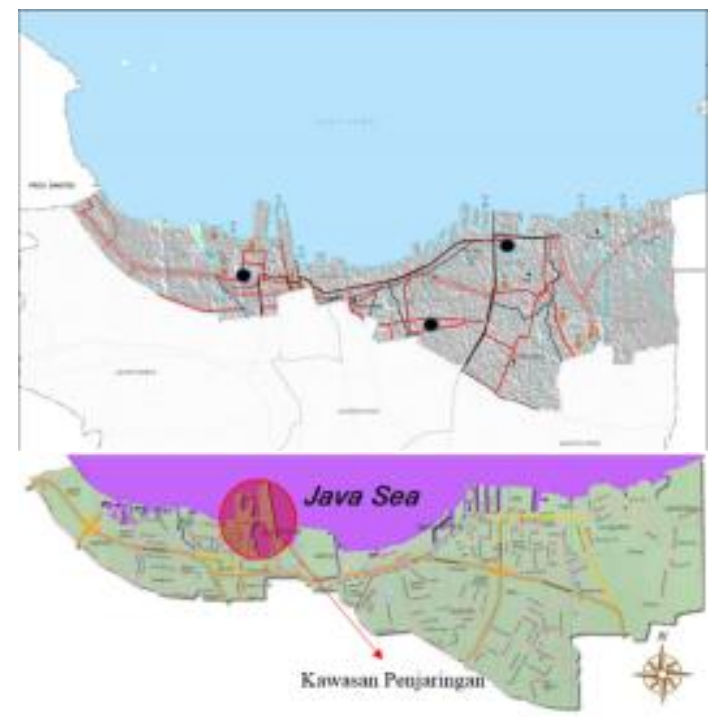

Gambar 3. Peta Kawasan Penjaringan

Pada titik inilah diperlukan intervensi penyelesaian masalah melalui Architectural Tourism. Wujud arsitektur yang ditusukkan berskala kecil, hingga muncullah istilah "Wisata Hiburan yang dapat mengedukasi semua kalangan etnis yang ada di Jakarta".

Dengan demikian, keberadaannya memberikan pengaruh positif pada kawasan itu sendiri, dimana konteks kota yang tetap lestari sekaligus memenuhi tuntutan kebutuhan masyarakat.

Melalui analisis yang telah dilakukan terhadap kawasan, sesuai pandangan dari berbagai kejadian adapun fasilitas yang akan diberikan di tama hiburan edukatif ini, diantara nya adalah :

- Ruang membaca

- Ruang bermain

- Wilayah workshop

- Taman bermain

- Ruang relaksasi

- Ruang kreativitas

- Sekolah kecil

- Lapangan serbaguna

\section{Analisis Tapak}

Entrance

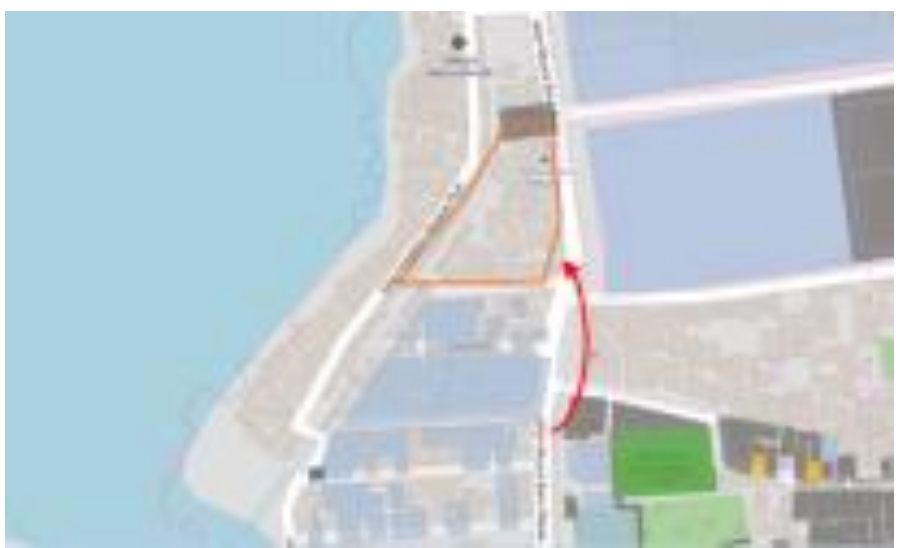

Gambar 4. Analisis Entrance 


\section{Kebisingan}

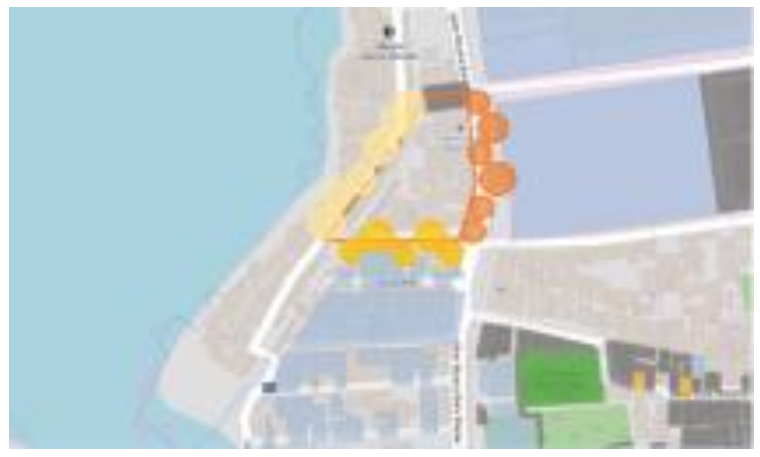

Gambar 5. Analisis Kebisingan

\section{Orientasi}

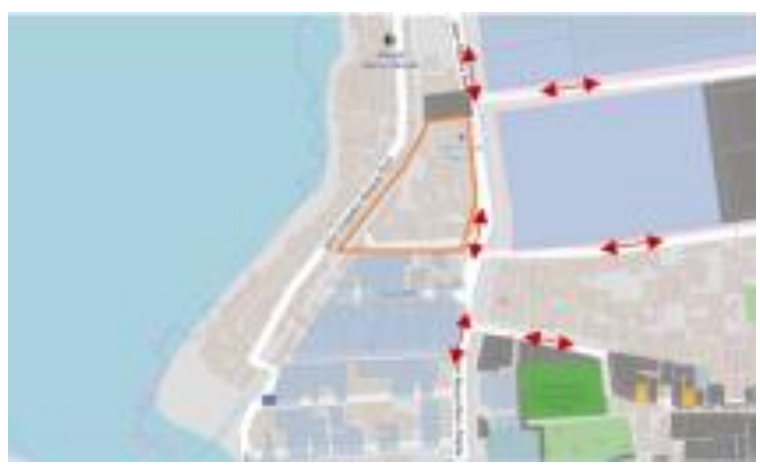

Gambar 6. Analisis Orientasi

\section{Pedestrian}

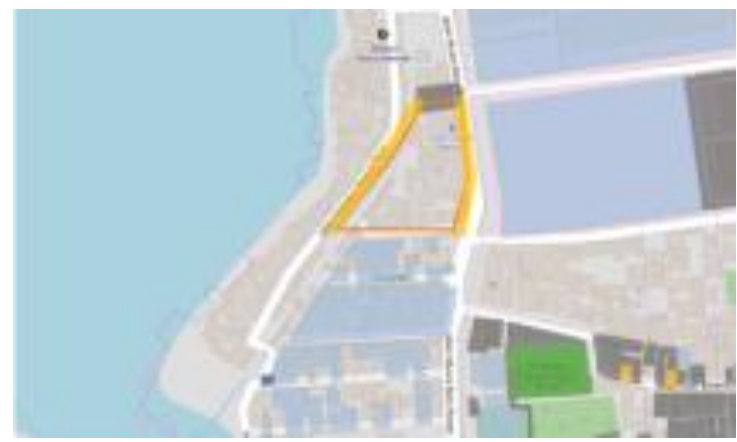

Gambar 7. Analisis Pedestrian

\section{Bentuk Massa Bangunan}

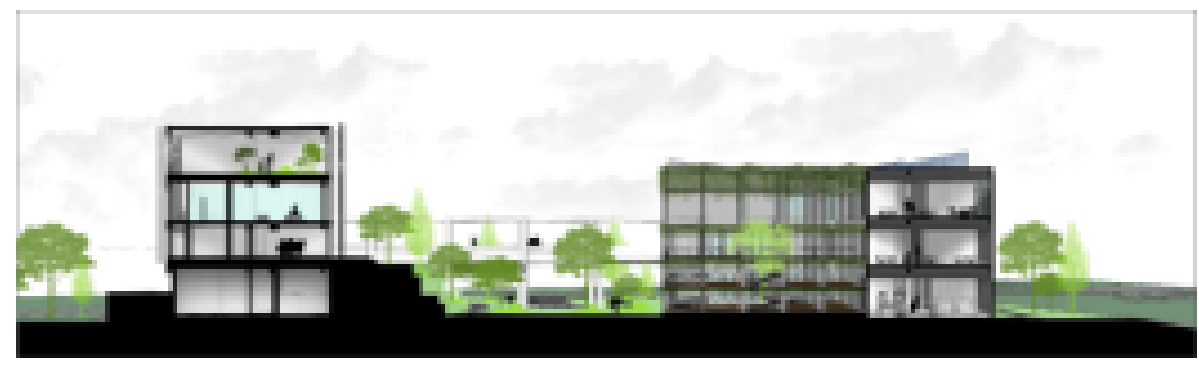

Gambar 8. Potongan Massa Bangunan 


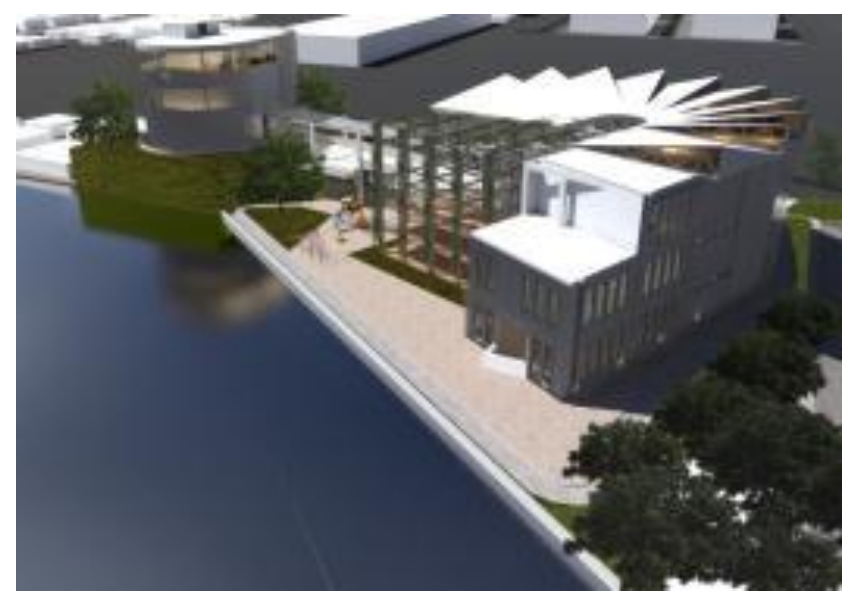

Gambar 9. Eksterior Massa Bangunan

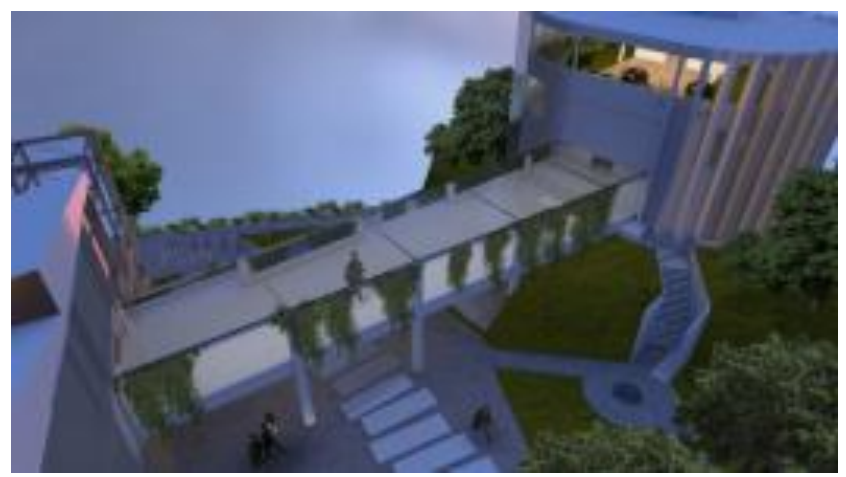

Gambar 10. Eksterior Massa Bangunan 1

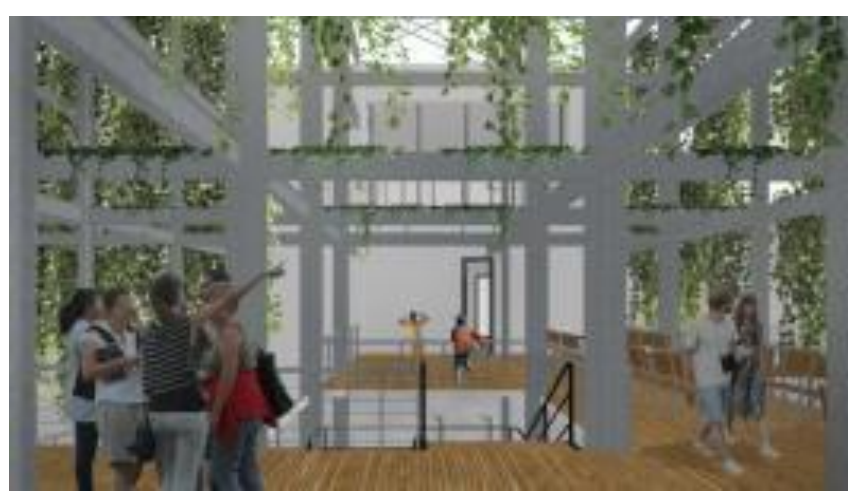

Gambar 11. Interior Massa Bangunan 1

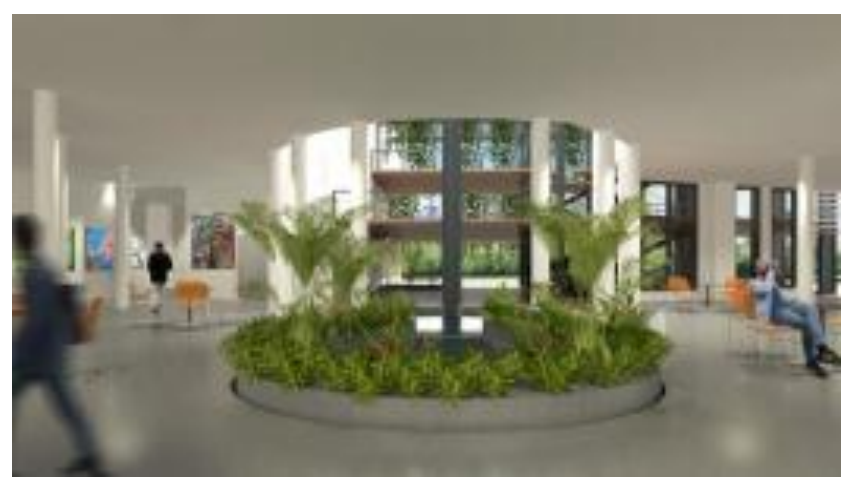

Gambar 12. Interior Massa Bangunan 2 


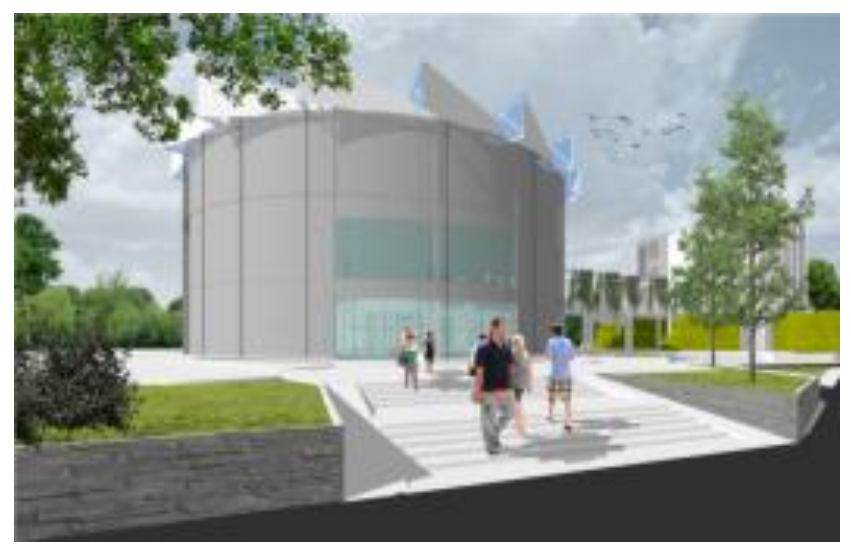

Gambar 13. Eksterior Massa Bangunan 2

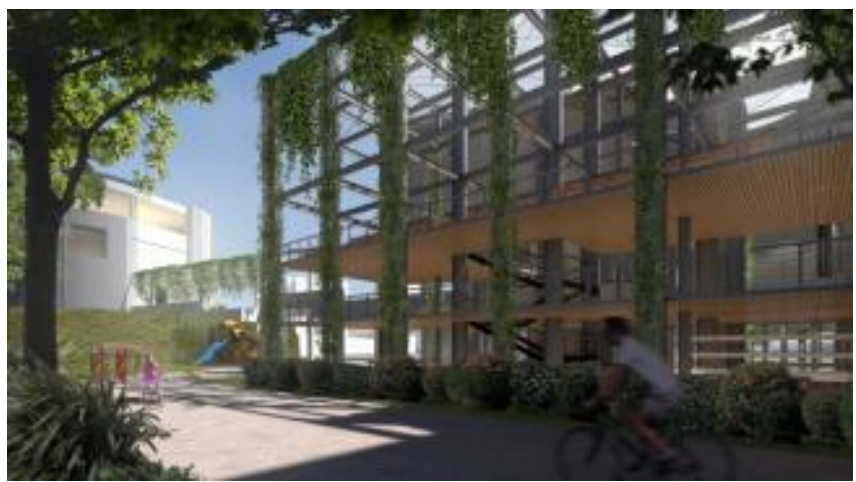

Gambar 14. Eksterior Massa Bangunan 3

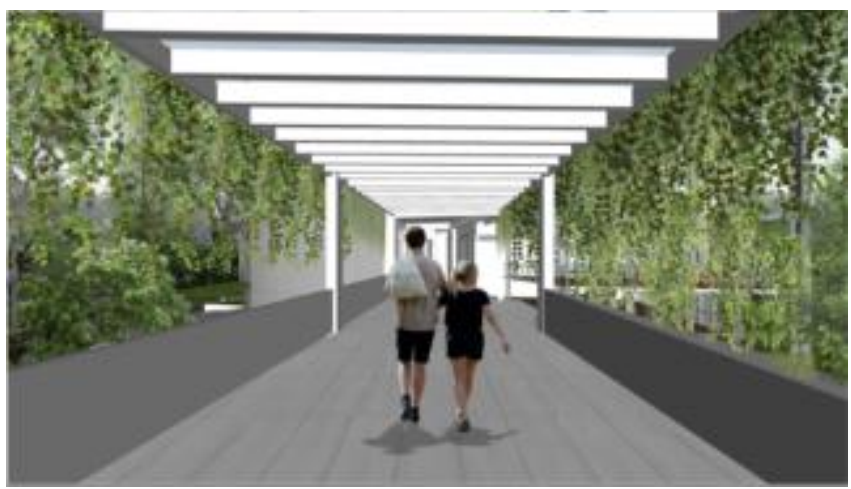

Gambar 15. Selasar Massa Bangunan 3

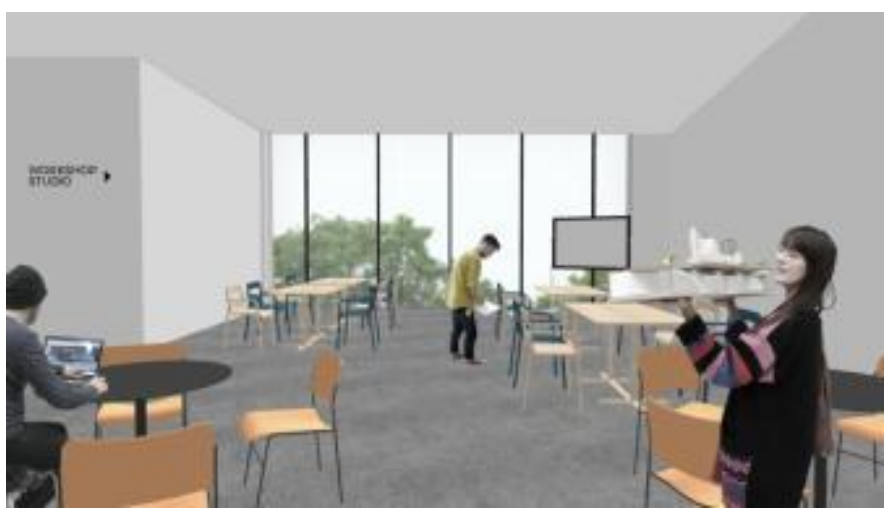

Gambar 16. Interior 1 


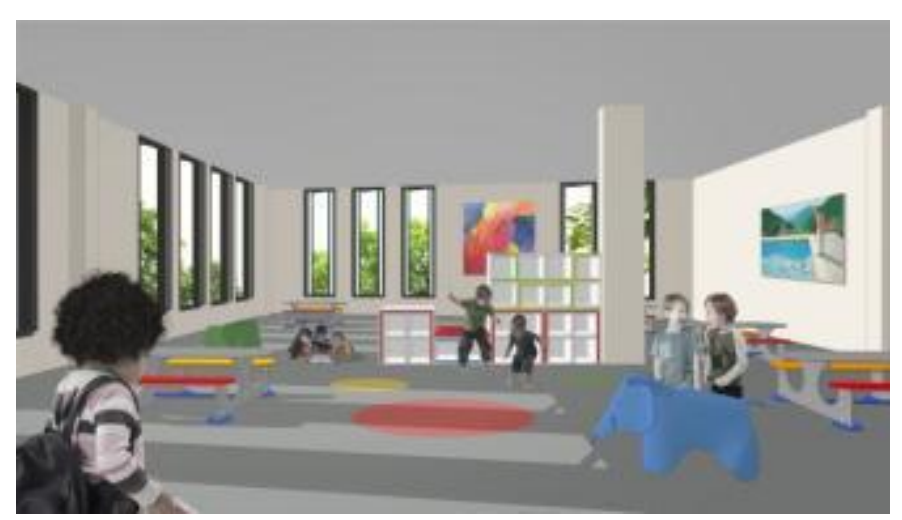

Gambar 17. Interior 2

\section{KESIMPULAN DAN SARAN}

Salah satu permasalahan yang tengah dihadapi oleh warga Jakarta belakangan ini adalah mengenai perilaku masyarakat yang masih memiliki pendidikan yang rendah, oleh karena itu membuat mereka tidak memiliki nalar berpikir yang sehat, sehingga mudah dihasut dan dipengarhi oleh profokator politik. Gejolak permasalahan politik yang paling memukau adalah kearah sara, terutama permasalahan agama agar masyarakat lebih mudah untuk dihasut atau diarahkan demi kepentingan para politikus. Oleh karena itu hiburan yang akan diberikan kepada masyarakat adalah dengan cara menyediakan tempat hiburan yang dapat mengedukasi sekaligus memberi kesenangan kepada semua lapisan masyarakatnya, setiap fasilitas/ hiburan dapat berbaur dengan semua jenis kalangan masyarakat yang ada di Jakarta khususnya warga di sekitar proyek tersebut.

\section{REFERENSI}

Specht, Jan. (2014) Architectural Tourism : Building for Urban Travel Destinations.

Sutanto, Agustinus. (2018) Pedoman Mata Kuliah Studio Perancangan Arsitektur 8.26:

Architourism of the Metropolis

https://www.google.co.id

http://www.tribunnews.com

https://www.suara.com

https://www.bbc.com

https://x.detik.com

https://leumburkuring.wordpress.com

https://id.wikipedia.org

http://www.pikiran-rakyat.com

http://www.indonesia-tourism.com

https://www.archdaily.com 